\title{
The optimal windows for seismically-enhanced gold precipitation in the epithermal environment
}

\author{
Pablo Sanchez-Alfaro ${ }^{1,2 * a}$, Martin Reich ${ }^{1,2}$, Thomas Driesner $^{3}$, José Cembrano ${ }^{2,4}$, Gloria \\ Arancibia $^{2,4}$, Pamela Pérez-Flores ${ }^{2,3}$, Christoph A. Heinrich ${ }^{3}$, Julie Rowland ${ }^{5}$, Daniele \\ Tardani $^{1,2}$, Dietrich Lange ${ }^{6}$, Eduardo Campos $^{7}$
}

${ }^{1}$ Department of Geology, Universidad de Chile, 8370450 Santiago, Chile

${ }^{2}$ Andean Geothermal Center of Excellence (CEGA), Universidad de Chile, Santiago, Chile

${ }^{3}$ Department of Earth Sciences, Swiss Federal Institute of Technology, ETH Zentrum NO, 8092

Zürich, Switzerland.

${ }^{4}$ Department of Structural and Geotechnical Engineering, Pontificia Universidad Católica de Chile, 7820436 Santiago, Chile

${ }^{5}$ School of Environment, The University of Auckland, Auckland, New Zealand.

${ }^{6}$ GEOMAR, Helmholtz-Zentrum für Ozeanforschung Kiel, Kiel, Germany

${ }^{7}$ Departamento de Ciencias Geológicas, Universidad Católica del Norte, Antofagasta, Chile

*Corresponding author: Pablo Sánchez-Alfaro,vsanchez@ing.uchile.cl

${ }^{a}$ Present address: School of Environment, The University of Auckland, Auckland, New Zealand.

\begin{abstract}
Epithermal gold $\mathrm{Au}$ ) deposits result from the combination of a sustained flux of metalrich fluids and an efficient precipitation mechanism. Earthquakes may trigger gold precipitation
\end{abstract}


by rapid loss of fluid pressure but their efficiency and time-integrated contribution to gold endowment are poorly constrained. In order to quantify the feedbacks between earthquake-driven fracturing and gold precipitation in the shallow crust, we studied the gold-rich fluids in the active Tolhuaca geothermal system, located in the highly seismic Southern Andes of Chile. We combined temperature measurements in the deep wells with fluid inclusion data, geochemical analyses of borehole fluids and numerical simulations of coupled heat and fluid flow to reconstruct the physical and chemical evolution of the hydrothermal reservoir. The effect of seismic perturbations on fluid parameters was constrained using a thermo-mechanical piston model that simulates the suction pump mechanism occurring in dilational jogs. Furthermore, we evaluated the impact of fluid parameters on gold precipitation by calculating the solubility of gold in pressure $(\mathrm{P})$ - enthalpy $(\mathrm{H})$ space. The reconstructed fluid conditions at Tolhuaca indicate that single-phase convective fluids feeding the hydrothermal reservoir reach the two-phase boundary with a high gold budget ( 1-5 ppb) at saturated liquid pressures between 20 and 100 $\operatorname{bar}\left(210^{\circ} \mathrm{C}<T_{\text {sat }}<310^{\circ} \mathrm{C}\right)$. We show that if hydrothermal fluids reach this optimal threshold for gold precipitation at a temperature near $250^{\circ} \mathrm{C}$, small adiabatic pressure drops $(\sim 10$ bar) triggered by transient fault-rupture can produce precipitation of $95 \%$ of the dissolved gold. Our results at the active Tolhuaca geothermal system indicate that subtle, externally-forced perturbations equivalent to low magnitude earthquakes $(\mathrm{Mw}<2)$ of a hydrothermal reservoir under optimal conditions - may significantly enhance gold precipitation rates in the shallow crust and lead to overall increases in metal endowment over time.

Keywords: Epithermal, gold, seismicity, suction pump, LOFS, Chile 
Highlights (maximum 85 characters, including spaces, per bullet point)

- A geothermal system was studied as a modern analogue of epithermal Au deposits

- Fluid data were combined with thermodynamic modeling and numerical simulations

- Small-magnitude $(\mathrm{Mw}<2)$ earthquakes can produce large drops in Au solubility

- Earthquake-driven flash vaporization is more efficient than cooling and boiling

- Protracted seismicity enhances Au precipitation rates in the epithermal environment

\section{INTRODUCTION}

The interplay between seismic activity, fluid flow and mineral precipitation exerts a firstorder control on the strength and permeability of the crust, and plays a critical role in promoting the development of hydrothermal systems and the formation of giant ore deposits (Richards, 2013; Sibson, 1987). External forcing such as earthquakes can have a profound impact on metal solubility, triggering physical and chemical changes in ore fluids that can enhance the precipitation process by phase separation (Rowland and Simmons, 2012; Sibson et al., 1988). This is particularly relevant in shallow crustal settings where porphyry copper and epithermal gold deposits form as a result of phase separation or boiling of a single-phase fluid. In the epithermal environment, in particular, precipitation of gold and/or silver may occur in association with gentle boiling, where fluid enthalpy is sufficiently high to produce a small vapor fraction upon ascent, or with flash vaporization forced by a transient pressure drop that converts most of the original liquid into a low density vapor phase (Moncada et al., 2012; Simmons et al., 2005; Weatherley and Henley, 2013). There is abundant evidence in the literature documenting that both permeability and gold precipitation are strongly affected by pressure changes triggered by earthquakes (Rowland and Simmons, 2012; Sibson et al., 1988; Weatherley and Henley, 
2013). Furthermore, studies have inferred that flash vaporization of gold-rich fluids in dilational jogs during an earthquake can result in the rapid co-deposition of silica to form gold-enriched quartz veins (Moncada et al., 2012; Sibson, 1987; Weatherley and Henley, 2013). However, these concepts have never been tested for the effect of externally-triggered pressure variations on gold solubility in the epithermal environment. Therefore, the relative contribution of seismic activity on gold precipitation rates - and thus, on the overall metal endowment of epithermal gold deposits - remains largely unknown.

In this study, we integrate geochemical data of gold-bearing borehole fluids with temperature profiles in an active, high-enthalpy geothermal system at Tolhuaca, in the seismically active Chilean Southern Andes. By combining these data with thermodynamic calculations of gold solubility and simulations on pressure drops driven by earthquakes, we constrain the optimal depth window for seismically enhanced gold precipitation. Our analysis points to favorable conditions for highly efficient gold extraction from hydrothermal fluids by flash vaporization in the epithermal environment. We further quantify the magnitude of these externally triggered perturbations, and explore the role of frequent, low-magnitude seismic activity as a relevant factor in building epithermal gold deposits in tectonically active regions.

\section{GEOLOGICAL SETTING}

The Andean Cordillera of Central-Southern Chile, where hydrothermal systems occur in close spatial relationship with active volcanism as well as major seismically-active fault systems, provides an excellent natural laboratory to study the interplay between earthquakes, fluid flow and metal precipitation (Fig. 1). In this region it has been shown that the nature and evolution of volcanic and hydrothermal systems is controlled by the NNE- trending, 1,200 km long Liquiñe- 
Ofqui Fault System (LOFS) and the NW-trending Arc-Oblique Fault System (ALFS) (Cembrano and Lara, 2009; Sánchez et al., 2013; Tardani et al., 2016: Perez-Flores et al., 2016). Within this setting, the active Tolhuaca geothermal field in the northern termination of the LOFS hosts a high enthalpy system that has been drilled to $\sim 3 \mathrm{~km}$ depth but is not yet affected by geothermal production or re-injection (Melosh et al., 2012:Sanchez-Alfaro et al., 2016)

Geological mapping, drillcore logging studies and kinematic analysis of fault-slip data have revealed that the Tolhuaca geothermal system is characterized by a structural and mineralogical compartmentalization in a transtensional stress regime (Sanchez-Alfaro et al., 2016). Based on core logging, mineralogical observations and fluid inclusions data four stages (S1-S4) of progressive hydrothermal alteration have been recognized at the Tolhuaca geothermal system (Sanchez-Alfaro et al., 2016). An early heating event (S1) was followed by the formation of a clay-rich cap in the upper zone $(<670 \mathrm{~m})$ and the development of a propylitic alteration assemblage at greater depth (S2). Boiling, flashing and brecciation occurred later (S3), followed by a final phase of fluid mixing and boiling (S4). The ubiquitous co-precipitation of silica phases (amorphous silica, chalcedony and quartz) and the formation of hydrothermal breccias at the end of S1 are indicative of widespread boiling and flashing conditions, suggesting a catastrophic event (Sanchez-Alfaro et al., 2016). Calcite with lattice-bladed texture, quartz with plumose texture and the coexistence of silica phases with variable degrees of crystallinity formed in stage S3, are indicative of boiling and flashing events which are likely triggered by transient pressure drops during the hydrothermal evolution at Tolhuaca (Sanchez-Alfaro et al., 2016). Transient pressure changes triggered by seismicity are likely produced at the tip of faults and in linkage zones, such as dilational jogs (Curewitz et al., 1997; Sibson, 1987, Weatherley and Henley, 2013). At Tolhuaca, structural logging of the Tol-1 core indicates the presence of dilational jogs 
infilled with calcite and quartz (Fig. 1 D\&E; Sanchez-Alfaro et al., 2016). In the vicinities of Tolhuaca volcano, detailed structural studies of fault systems revealed that dilatational jogs are formed at linking zones between NNE- and NE-striking faults. Syntaxial bladed-like calcite crystals of about $1 \mathrm{~cm}$ in size fill these dilatational jogs which indicate transient pressure drop likely related to fault activity in the LOFS (Perez-Flores et al., 2016).Therefore, the Tolhuaca

geothermal system is a good analogue to evaluate the impacts of internal and external triggers on fluid evolution and mineralization in a hydrothermal reservoir.

\section{METHODS}

Considering the role of phase separation in the precipitation of precious minerals in the epithermal environment, we use pressure-enthalpy $(\mathrm{P}-\mathrm{H})$ space to represent the thermodynamic conditions of the system. The P-H space allows the visualization of vapor fractions in the twophase region, reduced to a line in pressure-enthalpy space, and an intuitive representation of adiabatic (isoenthalpic) processes. This is justified because transient co-seismic thermodynamic changes are likely to be adiabatic in nature (Henley and Hughes, 2000).

In order to represent temperature logs of deep wells and homogenization temperatures of fluid inclusion data in P-H space. Enthalpy was calculated as a function of temperature assuming liquid phase conditions and depth was converted to pressure assuming a hydrostatic gradient, as indicated by the temperature and pressure data from deep wells (Sanchez-Alfaro et al., 2016)

\subsection{Gold solubility calculations in pressure-enthalpy space}

The GEMS geochemical modeling software (Kulik et al., 2012) was used to compute dissolved gold concentration in hydrothermal fluids under epithermal conditions. As the gold 
solubility calculation is highly dependent on fluid chemistry (especially on sulfur content, salinity and $\mathrm{pH}$ ), an accurate reconstruction of the chemical conditions of the deep reservoir is fundamental. Reservoir fluid samples are commonly collected at the wellhead after fluid ascent in the well has triggered depressurization boiling and separation between vapor and liquid. To reconstruct fluid chemistry at pre-sampling conditions the methodology developed by Scott et al. (2014) was used. Such methodology corrects the effect of the separation and segregation of liquid and vapor phases driven by adhesion of the liquid phase onto mineral surfaces in the porous aquifer rock upon rapid depressurization boiling. The reconstruction was performed using the WATCH geochemical modeling software (Arnórsson et al., 1982), assuming a unique segregation step and using temperature measurements to constrain reservoir temperature. The reconstructed chemistry was obtained for major elements included in the thermodynamic database of WATCH which are: $\mathrm{SiO}_{2}, \mathrm{~B}, \mathrm{Na}, \mathrm{K}, \mathrm{Ca}, \mathrm{Mg}, \mathrm{Al}, \mathrm{Fe}, \mathrm{CO}_{2}, \mathrm{H}_{2} \mathrm{~S}, \mathrm{SO}_{4}, \mathrm{Cl}$ and F. Volatiles such as $\mathrm{CO}_{2}$ and $\mathrm{H}_{2} \mathrm{~S}$ are significantly affected by phase segregation whereas the nonvolatiles components such as $\mathrm{Na}, \mathrm{Cl}$ and $\mathrm{Si}$ are only mildly affected.

For gold solubility calculations, feldspar-buffered acid-base conditions were assumed, i.e., excess Kfeldspar+albite+muscovite+quartz (Heinrich, 2005). The GEMS code uses the PSI/Nagra database (Hummel et al., 2002) as the core thermodynamic data source, which is complemented with SUPCRT92 (Johnson et al., 1992) for aqueous species and minerals. We updated the gold thermodynamic data for $\mathrm{Au}(\mathrm{Cl})_{\mathrm{n}}, \mathrm{Au}(\mathrm{OH})_{\mathrm{n}}$ and $\mathrm{Au}(\mathrm{HS})_{\mathrm{n}}$ species $(\mathrm{n}=1,2)$ with self-consistent experimental results (Stefánsson and Seward, 2004, 2003a, 2003b). Direct calculation of gold solubility with GEMS is restricted to the stability field of aqueous liquid, hereby computed within an equidistant temperature-pressure grid $\left(\Delta \mathrm{T}=5^{\circ} \mathrm{C} ; \Delta \mathrm{P}=10\right.$ bar $)$, ranging from 10-300 bar and 50-375 ${ }^{\circ} \mathrm{C}$. 
In aqueous sulfide solutions gold dissolves according to the following reactions $(1 \& 2)$ (Stefansson and Seward, 2004):

$$
\begin{gathered}
\mathrm{Au}(s)+\mathrm{H}_{2} \mathrm{~S}(a q)=\operatorname{AuHS}(a q)+0.5 \mathrm{H}_{2}(a q) \\
\mathrm{Au}(s)+\mathrm{H}_{2} \mathrm{~S}(a q)+\mathrm{HS}^{-}=\mathrm{Au}(\mathrm{HS})_{2}^{-}+0.5 \mathrm{H}_{2}(a q)
\end{gathered}
$$

In epithermal environments, gold solubility is dominated by the $\mathrm{Au}(\mathrm{HS})_{2}{ }^{-}$complex and therefore is strongly affected by the loss of sulfur in the two-phase region. To account for the effect of $\mathrm{H}_{2} \mathrm{~S}$-loss, sulfur depletion was calculated using Henry's law. Then, the solubility of gold in the aqueous liquid was computed using GEMS for the S-depleted liquid fraction ( $\left.m_{\text {Au_liquid }}\right)$ at saturated pressure $\left(\mathrm{P}=\mathrm{P}_{\text {sat }}\right)$. Due to the low solvation capacity of low-density steam (Hurtig and Williams-Jones, 2014), it is reasonable to assume that the gold dissolved in the vapor is negligible. Therefore, the gold content at any point within the two-phase region was calculated as the gold dissolved in the liquid phase ( $\left.m_{\text {Au_liquid }}\right)$ times the liquid mass fraction.

\subsection{Gold precipitation efficiency and gold grades}

The efficiency of gold precipitation from a hydrothermal fluid can be represented by the ratio of gold precipitated with respect to the initial gold content in the fluid, according to (3):

$$
\text { Efficiency }[\%]=\left(m_{\mathrm{Au} \_ \text {initial }}-m_{\mathrm{Au} \_ \text {final }}\right) / m_{\mathrm{Au} \_ \text {initial }}
$$

where $m$ is the molality of $\mathrm{Au}$ in the initial fluid (at liquid saturated conditions of the reservoir) and final fluid (at any condition bellow critical pressure and temperature), as subscripted. We assume that the amount of gold precipitated is equivalent to the difference between initial and final gold solubility of the ore fluid.

The gold grade in idealized quartz veins was represented by the gold-quartz mass ratio resulting from the precipitation of a certain mass of fluid and calculated in $\mathrm{mg}$ of gold per $\mathrm{kg}$ of 
quartz. Quartz solubility in the liquid region was computed using the equation of Manning (1994) and calculated within the two-phase region by assuming that silica is only contained in the liquid fraction. The efficiency and the resulting gold grade of an idealized vein were computed for an adiabatic pressure drop and isobaric cooling mechanisms.

The thermodynamic properties of water and steam - such as $\mathrm{P}, \mathrm{T}, \mathrm{H}, \rho$ and vapor fraction - were calculated in P-H space using the freeware Matlab code XSteam (Holmgren, 2007), which implements the IAPWS IF-97 databases for the properties of water.

\subsection{Suction-pump modeling}

Ore bodies in epithermal gold deposits are commonly related to specific structural elements such as dilational jogs, fault step-overs and releasing bends (Rowland and Simmons, 2012; Sibson, 1987; Simmons et al., 2005). Co-seismic slip in these structural contexts causes transient changes in the physical and chemical conditions of hydrothermal fluids and triggers the precipitation of precious metals (Moncada et al., 2012; Sibson, 1987).

Therefore, in order to analyze the effect of earthquakes on gold solubility in the epithermal environment we constrained the co-seismic changes on fluid parameters within a dilational jog. We used the suction pump piston model from Weatherley and Henley (2013) to estimate the co-seismic pressure drop in a fault step-over. In the suction pump mechanism, pressure drop is driven by transient volume increase in the dilational jog or fault step-over as described in Figure 2 (Sibson, 1987). The pressure drop produces the vaporization of most of the fluid within the dilational jog promoting the inflow of new hydrothermal fluid transported through the active fault and fracture networks (Weatherley and Henley, 2013). 
The change in volume within a fault jog due to the action of an earthquake of certain magnitude can be calculated using well-established earthquake fault scaling relationships between fault width and length, co-seismic slip and earthquake magnitude (Leonard, 2014).

In the updated empirical scaling relations for strike-slip earthquakes from Leonard (2014), the rupture length (L) is given by:

$$
\log _{10} L=\frac{\left(M_{w}+10.7\right) * 1.5-14.862}{2.5}
$$

the average slip (s) is:

$$
\log _{10} s=0.833 \log _{10} L-3.84
$$

and Width (W) of the rupture is: $\mathrm{W}=\mathrm{L}$ for small magnitude earthquakes $(\mathrm{Mw}<5)$; $\mathrm{W}=15^{*} \mathrm{~L}^{2 / 3}$ for moderate earthquakes $(5<\mathrm{Mw}<6.5) ; \mathrm{W}=17 \mathrm{~km}$, the mean crustal seismogenic width for large earthquakes $(\mathrm{Mw}>6.5)$. Since we used an updated and corrected version of the earthquake scaling relations by Leonard $(2014,2012)$ the calculations are slightly different to those of Weatherley and Henley (2013) who used the scaling relations from Leonard (2010).

The least constrained geometrical parameter in the model is the jog length (or step-over distance; D in Fig. 2) arbitrarily considered as $1 \mathrm{~m}$. However, co-seismic pressure drop estimations are only dependent on the relative volume increase which is unaffected by variations on the jog length (D), as arises from the relative volume increase definition in (6):

$$
\frac{V_{i}+\Delta V}{V_{i}}=1+\frac{s \times D \times W}{d \times D \times W}=1+\frac{s}{d}
$$

The initial effective aperture thickness of the dilational jog ' $d$ ' assumed for the model is $0.1 \mathrm{~mm}$. This ' $\mathrm{d}$ ' value is reasonable for representing a dilational jog with a restricted aperture just prior the co-seismic slip and/or the reactivation of a larger dilational jog that has been sealed 
by mineralization. However, our calculations would overestimate the pressure drop in the case of a dilational jog that is initially widely open (much higher 'd' values).

This model assumes that the fault jog is initially filled with fluid and that the transient boiling is adiabatic and sustained by heat transfer from wallrock to fluid, as a result of the decrease in temperature due to phase change (Henley and Hughes, 2000). By combining the relative volume changes with the thermodynamic properties of water, the transient fluid pressure and vapor fraction was computed for earthquakes of variable magnitude.

The fault-valve mechanism also may occur in hydrothermal systems, but unlike the suction pump, it is driven by pore fluid overpressure (Sibson et al., 1988). This mechanism is generally considered in the context of orogenic gold deposits, in which unfavorably oriented reverse faults are activated by substantial increases in fluid pressure, optimizing conditions for gold deposition across fault-valves (Sibson and Scott, 1998). However, hydraulic activation of brittle failure also exerts a profound influence on fluid migration in epithermal environments, which typically are associated with extensional (transtensional) tectonics (Sillitoe and Hedenquist, 2003). In these settings, very small increases in pressure may result in fluid flow through mixed-mode meshes of faults and fractures (Sibson, 2003), perhaps explaining the prevalence of seismic swarm activity in active environments (Rowland and Simmons, 2012; Sibson, 2003; Sibson et al., 1988). However, although we consider fault-valve behavior important at all scales in all tectonically active fluid regimes, we focus on the analysis of the suction pump mechanism because of its geometrical simplicity for demonstrating the effect of seismically-triggered pressure drops on gold precipitation. 


\section{RESULTS}

\subsection{Thermodynamic conditions at Tolhuaca in pressure-enthalpy space}

Major-element fluid chemistry of geothermal fluid was reconstructed at reservoir conditions following the phase segregation methods and used as the main input for gold solubility calculations (see section 2.3). The concentration of major components estimated at reservoir conditions ( $\mathrm{P}_{\mathrm{sat}}=85$ bar) is $\mathrm{Cl}=193, \mathrm{H}_{2} \mathrm{~S}=19.7, \mathrm{SO}_{4}=6.3, \mathrm{Na}=131, \mathrm{~K}=24, \mathrm{Al}=0.76$, $\mathrm{SiO}_{2}=364$, in $\mathrm{mg} / \mathrm{kg}$ of water. Metal content is indicated in Figure 3 by the measured concentrations of trace elements including $\mathrm{Au}(1.6 \mu \mathrm{g} / \mathrm{kg}), \mathrm{Ag}(0.018 \mu \mathrm{g} / \mathrm{kg}), \mathrm{Cu}(0.07 \mu \mathrm{g} / \mathrm{kg})$ and $\mathrm{Zn}(7.5 \mu \mathrm{g} / \mathrm{kg})$.

Present-day pressure and enthalpy conditions, calculated from temperature measurements in deep wells of the Tolhuaca geothermal system (Melosh et al., 2012; Sanchez-Alfaro, 2015) are shown in pressure-enthalpy $(\mathrm{P}-\mathrm{H})$ space in Figure 4A. Additionally, measured homogenization temperatures of fluid inclusion assemblages hosted in quartz and calcite from Sanchez (2015) are used to estimate pressure and enthalpy and represent past conditions of the system in P-H space (Fig. 4B). Temperature, pressure and enthalpy data indicates that the geothermal reservoir reaches vapor saturated liquid at $\sim 85$ bar of pressure and $\sim 300^{\circ} \mathrm{C}$ of temperature.

\subsection{Gold solubility in pressure-enthalpy space}

To quantify the effect of the different fluid trajectories on the dissolved gold we calculated the solubility of gold in pressure-enthalpy space, allowing a clear representation of adiabatic pressure changes. We used the reconstructed chemistry from the Tolhuaca fluid at the estimated reservoir conditions as a reasonable starting point for calculations. 
In Figure 5, the calculated isopleths (red lines) show high solubility conditions for gold in the liquid-phase region between $\sim 210$ to $370^{\circ} \mathrm{C}$ ( $\mathrm{P}_{\text {sat }}$ eq. 20 to 220 bar). For these conditions, the calculated isopleths indicate that a subtle adiabatic pressure drop of $\sim 10$ bar from liquid-saturated conditions (shaded in yellow), where saturated liquid pressure $\left(P_{\text {sat }}\right)$ ranges between 20 and 100 bar $\left(210^{\circ} \mathrm{C}<T_{\text {sat }}<310^{\circ} \mathrm{C}\right)$, causes a sharp decrease in gold solubility (Fig. 5A, blue vertical arrow). If the adiabatic pressure drop occurs at higher pressures ( $P>P_{\text {sat }} \sim 100$ bar $)$, the solubility decrease is moderate.

Calculations of the efficiency of gold precipitation indicate that starting from the estimated Tolhuaca geothermal reservoir condition $\left(\mathrm{T}_{\mathrm{sat}} \sim 300^{\circ} \mathrm{C}, \mathrm{P}_{\text {sat }} \sim 85\right.$ bar, orange circle in Fig. 6A) an adiabatic pressure drop of 10 bar produces the precipitation of more than $50 \%$ of the gold initially dissolved while a pressure drop of 20 bar precipitates near 70\%. Starting from a lower enthalpy condition $\left(\mathrm{T}_{\mathrm{sat}} \sim 250^{\circ} \mathrm{C}, \mathrm{P}_{\mathrm{sat}} \sim 40 \mathrm{bar}\right)$ an adiabatic pressure drop of 5 bar has a gold precipitation efficiency of $70 \%$ while a 10 bar pressure drop leads to a $95 \%$ efficiency. Conversely, if the fluid follows a cooling path and starts at reservoir conditions, it requires a temperature decrease of $100^{\circ} \mathrm{C}$ for $50 \%$ efficiency and $160^{\circ} \mathrm{C}$ for $95 \%$ efficiency.

Figure 6B shows the gold solubility versus pressure for gentle boiling and adiabatic decompression paths. For the gentle boiling path -following the boiling curve-, gold solubility decrease is driven by the decrease of saturated -liquid temperature and is very sharp only at pressures bellow 15 bar $\left(\mathrm{T}_{\text {sat }}\right.$ eq $\left.200^{\circ} \mathrm{C}\right)$. Contrastingly, the solubility drop in the adiabatic decompression path is produced mainly by $\mathrm{H}_{2} \mathrm{~S}$ loss and is significantly steeper than the gentle boiling path.

The quartz solubility data (Fig. 6C) allow calculating the gold-quartz mass ratio for idealized quartz veins (Fig. 6D), as a proxy for the gold grade resulting from cooling and 
adiabatic decompression paths. The estimated gold grade resulting from cooling is $\sim 1 \mathrm{mg} \mathrm{Au/}$ $\mathrm{kg}$ quartz] near reservoir conditions, whereas it reaches more than 10 [mg Au/ kg quartz] for small adiabatic pressure drops ( $\leq 10$ bar) at pressures bellow 100 bar. The increase of goldquartz mass ratio at pressures higher than 150 bar for the adiabatic pressure drop paths is caused by the retrograde quartz solubility and does not represent an increase in the gold precipitation efficiency.

\subsection{Transient pressure drop driven by the suction pump mechanism}

The suction pump piston model was used to evaluate the effects of co-seismic changes on the thermodynamic conditions of hydrothermal fluids in the epithermal environment. The transient pressure drop that occurs within a dilational jog produced by fault rupture during earthquakes is shown in Figure 5A. Under the estimated reservoir conditions at Tolhuaca $\left(\mathrm{T}_{\text {sat }} \sim 300^{\circ} \mathrm{C}, \mathrm{P}_{\text {sat }} \sim 85\right.$ bar), our calculations indicate that a pressure drop of 54 bar, equivalent to a seismic event of $\mathrm{Mw}=2$, would generate a mass vapor fraction of 0.18 and at least a 2 log-units decrease in gold solubility (Fig. 5A and Fig. 6A). Calculations for variable pre-seismic initial conditions (pressure and enthalpy) within the liquid-saturated curve are shown in Figure 6A.

\section{DISCUSSIONS}

\subsection{Optimal window for gold precipitation}

The combination of fluid chemistry data and thermodynamic modeling at Tolhuaca indicates that gold solubility is critically affected by $P-T-H$ trajectories followed by the precious metal-rich carrier fluid. The trace metal content of fluids in the Tolhuaca geothermal reservoir are broadly similar to those measured in geothermal systems in the Taupo Volcanic Zone (New 
Zealand) and in the active Lihir hydrothermal gold deposit (Papua New Guinea), supporting the use of Tolhuaca as an analogue of the epithermal environment (Fig. 3). Measured gold content of fluid at Tolhuaca (1.6 ppb) is within the range of gold solubility calculated at reservoir conditions (1 - $2 \mathrm{ppb}$; Figure 5).

Although gold solubility calculation is dependent on fluid chemistry, the topology of the diagrams in Figures 5 and 6 is not affected by slightly different initial fluid chemistry - including $\mathrm{pH}$ and sulfur content - within the range of the low sulfidation epithermal environment conditions and therefore are likely to describe precipitation and transport processes in such environment. Calculated gold solubility is consistent with updated databases and experimental results (Stefánsson and Seward, 2004) as well as with more recent studies of gold behavior in epithermal environments (Williams-Jones et al., 2009). Significantly higher gold concentrations than considered here are possible, if $\mathrm{H}_{2} \mathrm{~S}$ concentrations are higher, increasing approximately with the square of the $\mathrm{H}_{2} \mathrm{~S}$ activity, as shown by reactions (1) and (2) (Williams-Jones et al., 2009, Stefansson and Seward, 2004). Such conditions can be met if low-salinity magmatic fluids are injected into the base of the convective geothermal system. In this scenario, the same triggers for gold precipitation will apply but efficiency will increase. Magmatic fluid input may thus explain the temporarily much higher gold contents reported in fluid inclusions from epithermal gold deposits (up to 3,000 ppb; Márquez-Zavalía \& Heinrich, 2016) compared to active geothermal systems. Higher Au and S concentrations also imply that higher-grade deposits may form in a correspondingly shorter time (Heinrich, 2005; Heinrich, 2006; Simmons \& Brown, 2006; Márquez-Zavalía \& Heinrich, 2016).

Our calculations show high solubility conditions for gold in the liquid-phase region between $\sim 210$ to $370^{\circ} \mathrm{C}$ ( $\mathrm{P}_{\text {sat }}$ eq. 20 to 220 bar; Fig. 5), as widely recognized for epithermal 
environments (e.g., Simmons et al., 2005; Williams-Jones et al., 2009). More interestingly, gold solubility calculations in P-H space indicate that the effect of small pressure changes on gold solubility is enhanced at specific thermodynamic conditions (Fig. 5). Therefore, we recognize an optimal window for efficient gold precipitation that can be triggered by relatively subtle adiabatic pressure drops. Such window is at liquid-saturated conditions (boiling), relatively high temperatures $\left(210^{\circ} \mathrm{C}<T_{\text {sat }}<310^{\circ} \mathrm{C}\right)$ and corresponding saturated liquid pressures $\left(20\right.$ bar $<P_{\text {sat }}<100$ bar), coincident with the documented ore precipitation conditions in epithermal gold deposits (Simmons et al., 2005) (Fig. 5A). Such optimal conditions at the two-phase boundary are developed through a combination of sustained heat and high permeability conditions, as previous studies have shown (e.g. Hayba and Ingebritsen, 1997; Weis et al., 2012), and can be sustained at the geothermal reservoir until the waning and cooling of the hydrothermal system.

Our gold solubility results in Figure 6A show that precipitation efficiency of relatively small adiabatic pressure drops (20 bar) at reservoir conditions of Tolhuaca is high (70\%) and for an equivalent efficiency would alternatively require a significant cooling $\left(>120^{\circ} \mathrm{C}\right)$. Furthermore, the gold-quartz mass ratio of up to $30 \mathrm{~g} \mathrm{Au} / \mathrm{t}$ resulting from an adiabatic pressure drop within the optimal window - represented by a red vertical arrow in Figure 6A and 6D - is consistent with observed gold grades in small tonnage, high-grade orebodies (10-100 g Au/t, Simmons et al., 2005 ). In turn, isobaric cooling pathways - represented by a green horizontal arrow in Figure 6A and 6D - result in gold grades of less than $5 \mathrm{~g} \mathrm{Au} / \mathrm{t}$, similar to those described in large tonnage, low-grade orebodies (1-2 g Au/t, Simmons et al., 2005). These results support the idea invoked in petrographic and mineralogical studies of ore textures and fluid inclusions assemblages that flash vaporization is more efficient than gentle boiling for ore precipitation (Moncada et al., 2012). 
The estimated pressure drops driven by earthquakes through the suction pump mechanism indicate that even small magnitude earthquakes $(\mathrm{Mw}<2)$ can trigger efficient gold precipitation if the system is initially at the optimal conditions for gold precipitation (Figs. $5 \&$ 6). This result is relevant since previous studies have proposed that changes in physical parameters such as permeability and/or pressure triggered by fault rupture lead to efficient precipitation of gold in hydrothermal systems at any initial condition (e.g., Micklethwaite et al., 2015). Therefore, our results strongly suggest that ore fluids feeding the hydrothermal reservoir must evolve towards optimal conditions (20 bar $\mathrm{P}_{\text {sat }}<100$ bar; $210^{\circ} \mathrm{C}<T_{\text {sat }}<310^{\circ} \mathrm{C}$ ) before - or concomitantly with - the occurrence of a seismic event, so that gold solubility is efficiently reduced through flash vaporization.

\section{FURTHER IMPLICATIONS}

Since our results reveal that gold solubility is significantly affected by subtle adiabatic pressure releases (e.g., 10 bar) triggered by earthquakes, the key question is how seismic activity transiently promotes gold precipitation and enhances the ore forming process. In this section we explore the long-term contribution of earthquake-triggered precipitation to epithermal gold deposits formation by considering the suction pump mechanism. In this particular case, the time-integrated contribution can be estimated after calculating the mass of vaporized fluid, the initial gold content of the fluid and the earthquake frequency. The mass of vaporized fluid is directly related to the volume change within the dilational jog. This volume change is independent of the initial effective aperture thickness of the dilational jog ' $d$ '. We assume that even small earthquakes $(\mathrm{Mw}>0)$ trigger the vaporization of most of the fluid within dilational jogs and the precipitation of the gold (and quartz) dissolved in hydrothermal fluid, based on 
previous works (Sibson, 1987; Weatherley and Henley, 2013) and the results presented in section 4.1. Considering that the system flashes (boils adiabatically) until the pre-seismic pressure is reached via new fluid inflow, it is reasonable to assume that the volume of vaporized fluid by the suction pump mechanism can be estimated as the co-seismic volume increase $(\Delta V)$. Therefore, in each seismic event, the amount of precipitated gold is equal to the mass of metal contained in the volume of vaporized fluid -equivalent to the co-seismic volume increase $(\Delta \mathrm{V})$ - which is dependent on the magnitude of the earthquake:

$$
\mathrm{Au}_{E Q}=m_{\text {Au_liquid }} \rho \Delta V_{E Q}
$$

The gold precipitated in a given earthquake magnitude range results from the multiplication of the gold precipitated mass $\left(\mathrm{Au}_{E Q}\right)$ by the number of earthquakes occurring in a specific time-span (e.g., $1 \mathrm{ka}$ ). Then, the long-term effect is the integrated contribution of earthquakes of variable magnitude, as described in (8):

$$
\mathrm{Au}_{\text {total }}=m_{\text {Au_liquid }} \rho \int_{M w=-2}^{M w=8} \Delta V_{E Q} N_{E Q} d M w
$$

where $N$ is the number of earthquakes within a magnitude range $d M w$ per time-unit.

As earthquake frequency (incremental magnitude-frequency distribution) is scaledependent we assume that the spatial extension of active geothermal systems is the reasonable scale to represent the epithermal environment. Due to the lack of adequate seismic records at the local scale for the greenfields Tolhuaca, we used the earthquake density distribution data from the Liquiñe-Ofqui Fault System in its southern termination (Lange et al., 2008) as an estimation of the frequency of tectonic-induced earthquakes in the area.

Since seismicity and the amount of dissolved gold in the ore fluids are key variables that may affect the time-integrated contribution to gold precipitation in epithermal systems, we analyze their effect on gold precipitation rates. As a first order approximation, we integrate the 
amount of gold precipitated over time for different earthquake density distributions and variable gold concentrations in the fluid. Different earthquake density distributions were synthetically constructed by increasing and decreasing the earthquake frequency for a constant $b$-value of 1 , which is typical for tectonically-induced events and depends inversely on differential stress (Schorlemmer et al., 2005). Fluid-induced earthquakes swarms, on the other hand, have higher $b$ values that can be as large as 2.5 (Legrand et al., 2011).

Considering that the magnitude of an earthquake is directly related to the length of the co-seismic slip and the volume within dilational jogs, it is clear that the vaporized mass of the ore-forming fluid grow exponentially with increasing earthquake magnitude (Fig. 7A) (Weatherley and Henley, 2013). On the other hand, large-magnitude earthquakes are significantly less frequent than small-magnitude earthquakes, as shown by the Gutenberg-Richter relationship in Figure 7B. Therefore, the amount of fluid affected by seismically-triggered flash vaporization over a certain period of time (Fig. 7C) will depend on these two counteracting effects, i.e., minor earthquakes trigger precipitation of smaller amounts of gold relatively frequently, whereas infrequent major earthquakes affect large volumes of hydrothermal fluids and thus have the potential to precipitate very large quantities of gold.

The time-integrated contribution of earthquake-triggered precipitation shown in Figure 7C was calculated taking into account the gold content of the fluid in Tolhuaca ( 1 ppb), and an earthquake magnitude relationship for the LOFS (Lange et al., 2008) defined by a $b$-value $\sim 1$ for a 1,000 years period. The area below the curve in Figure $7 \mathrm{C}$ represents the total mass of gold precipitated per ka, and reveals that earthquakes with magnitude between $4 \mathrm{Mw}$ and $7 \mathrm{Mw}$ contribute $\sim 70 \%$ of the total gold precipitated in a hydrothermal reservoir undergoing seismic activity. The association of gold precipitation to low and intermediate-magnitude earthquakes, 
i.e., small and intermediate slips ( $4 \mathrm{Mw}: 3 \mathrm{~cm}-7 \mathrm{Mw}: 1.1 \mathrm{~m}$ ), is consistent with the observation that, second-order fractures are predominant in high-grade Au veins in geothermal systems and epithermal gold deposits (Simmons et al., 2005).

According to our calculations, the earthquake-enhanced gold precipitation rate at Tolhuaca is small $(0.5 \mathrm{~kg} / \mathrm{ka})$, requiring $\sim 58 \mathrm{Ma}$ to build up a $1 \mathrm{Moz}$ ( 31.1 tonnes) Au ore body (Fig. 7C). When this rate is calculated for different earthquake density distributions and variable gold concentrations for the sake of comparison, results show that gold precipitation rate at Tolhuaca (orange box in Figure 8) would increase by two orders of magnitude if fluids had a gold budget as large as those from, e.g., Lihir island gold-rich fluids (vertical segmented line, Figure 8 ). These calculations also indicate that a 10 -fold increase in seismicity produces a 10 -fold increase in gold precipitation rate for a given gold content in the fluid.

The calculated rates of gold precipitation enhanced by seismic activity in Figure 8, allow a first order comparison with gross estimations on the gold precipitation rates in epithermal deposits. We selected the Hauraki Goldfield (New Zealand) and the Hishikari (Japan) lowsulfidation epithermal deposits because they represent similar conditions than those at Tolhuaca. In these deposits mineralization is concentrated in veins, associated to low salinity hydrothermal fluids ( $<3 \mathrm{wt} \% \mathrm{NaCl}$ equiv.) and related to extensional or mildly extensional tectonic settings (Izawa et al., 1990; Mauk et al., 2011). The Waihi gold deposit hosts 167 tonnes of gold (Brathwaite and Faure, 2002) and available data indicate that most of the known gold endowment was deposited in a 390 to 460 ka window (Mauk et al., 2011). The Hishikari epithermal deposit contains c.a. 260 tonnes of gold (Izawa et al., 1990) and ${ }^{40} \mathrm{Ar} /{ }^{39} \mathrm{Ar}$ dating of adularia indicate that the deposit was formed in less than $260 \mathrm{ka}$ (Sanematsu et al., 2006). Therefore, a gross rate of tonnes of gold precipitated per 1,000 years $(\mathrm{t} / \mathrm{ka})$ are estimated in 0.43 
$\mathrm{t} / \mathrm{ka}$ for Waihi and $1 \mathrm{t} / \mathrm{ka}$ for Hishikari gold deposits. In comparison with Tolhuaca $(0.0005$ tonnes of gold precipitated per ka), these broad estimations are two to four orders of magnitude higher. These higher gold precipitation rates, which are still minimum rates considering the precision of geochronological estimate, place Waihi and Hishikari deposits in the upper right region of Figure 8, showing that higher gold content in the fluid and/or increased seismicity would be required to build a large epithermal gold deposit in the Tolhuaca system.

Although the actual rates in natural systems are very likely affected by other variables (e.g., changes in hydrology, stress regime, magmatic activity and compositional variations of the fluids, among many others), these results are a first step towards quantifying the effects of longterm seismicity on ore precipitation, and should motivate further and more detailed studies.

\section{CONCLUDING REMARKS}

This study integrates geochemical and structural data from the active Tolhuaca geothermal system in southern Chile to understand the interplay between seismic activity, fluid flow and gold precipitation in the epithermal environment. By combining borehole and fluid chemistry data with thermodynamic modeling we conclude that the efficiency of gold precipitation is highly dependent on the $P-T-H$ initial conditions of the high-enthalpy hydrothermal reservoir, and become optimal at liquid-saturated conditions and pressures below 100 bar $\left(210^{\circ} \mathrm{C}<T_{\text {sat }}<310^{\circ} \mathrm{C}\right)$. Our key result indicates that under such P-T conditions, very efficient gold extraction from hydrothermal solutions can be achieved by pressure drop and associated phase separation. These calculated conditions are coincident with the documented ore precipitation conditions described in epithermal gold deposits. 
This optimal environment develops through a combination of sustained heat and high permeability conditions, and can be perturbed by subtle adiabatic pressure decreases ( 5-20 bar). When the suction pump piston model is used to evaluate the effects of co-seismic changes on the thermodynamic conditions of hydrothermal fluids, the transient pressure drop that occurs within dilational jog produced by fault rupture during earthquakes (e.g., Mw=2) would generate a pressure drop of $\sim 55$ bar, a vapor fraction of $\sim 0.20$ and at least a 2 log-units decrease in gold solubility. These results indicate that even small magnitude earthquakes $(\mathrm{Mw}<2)$ can efficiently gold precipitation if the system is initially at the optimal conditions. Furthermore, we show that, although gentle boiling drives some gold deposition, flash vaporization occurring under these optimal window conditions maximizes the extraction of gold from the ore fluid.

The results presented in this study are in close agreement with the notion that gold precipitation in the shallower portions of hydrothermal systems is modulated by a sustained supply of metals from a magmatic-hydrothermal source, an efficient ore transport mechanism that ensures high gold-solubility conditions, followed by chemical changes or physical perturbations of a hydrothermal reservoir. Such conditions result from an ideal interplay between seismic activity, fluid flow, transient solubility changes and $P-T-H$ fluctuations that may significantly enhance gold precipitation rates in the shallow crust and lead to overall increases in metal endowment over time.

\section{Acknowledgments}

We acknowledge support from CEGA (FONDAP 15090013), FONDECYT \#1130030 and the Millennium Science Initiative grant NC130065 "Millennium Nucleus for Metal Tracing Along Subduction" to M.R. We thank MRP-Chile Ltd. and former GGE Ltd., in particular S. Iriarte, S. 
Lohmar, G. Melosh, J. Stimac and A. Colvin for providing access to Tolhuaca and information used in this study. S. Scott, M. Wälle and M. Steele-MacInnis from IGP-ETH Zürich are thanked for their help during data acquisition. We thank Ake Fagereng and an anonymous reviewer for their constructive comments, which helped to improve the final version of this work. S.

Micklethwaite and S. Cox are also thanked for their detailed comments to an early version of this manuscript. P.S, D.T. and P.P. acknowledge financial support given by MECESUP and CONICYT doctoral grants. J.C. thanks the National Research Centre for Integrated Natural Disasters Management (RCINDIM). T.D. and C.A.H. acknowledge continued support by the Swiss National Science Foundation (Grant 200021-146651).

\section{FIGURE CAPTIONS}

Fig. 1. Geodynamic and structural setting of the Tolhuaca geothermal system. (A), Digital Elevation Model showing the location and extent of the Liquiñe-Ofqui Fault System (LOFS; in black) and the Arc-Oblique Fault System (ALFS; in red)(Perez-Flores et al., 2016). (B), Simplified geological map showing the major structural systems. Also, the spatial and genetic association between the LOFS and ALFS with the major stratovolcanoes, monogenetic cones and geothermal areas are shown (Perez-Flores et al., 2016). (C) Conceptual model of the Tolhuaca geothermal system at local scale showing the main hydrological features, modified from Sanchez-Alfaro et al., (2016). (D \& E) Photomicrographs of veins with the geometry of a dilational jog retrieved from the Tol-1 core. Vein in (D) is infilled by bladed calcite (minor quartz, chalcedony and iron oxides) whereas vein in (E) is infilled mainly by chalcedony (minor quartz, epidote, pyrite and wairakite). 
Fig. 2. Geometry of the suction pump model used to represent dilational jogs during

faulting. (A), Pre-rupture conditions under a uniform fluid pressure regime. (B) Volume increase due to co-seismic slip causes flashing vaporization and solubility decrease of dissolved minerals. Fluid influx is enhanced from surrounding fault-fracture meshes.

Fig. 3. Trace metal content in hydrothermal fluids from Tolhuaca reservoir. Metal content in Lihir island gold-rich fluids and geothermal fluids from the Taupo Volcanic Zone are shown as reference.

Fig. 4. Physicochemical evolution of the Tolhuaca hydrothermal system. Microthermometric data and present-day conditions in pressure-enthalpy $(\mathrm{P}-\mathrm{H})$ space. Blue open circles show the average homogenization temperatures of fluid inclusions with 1-sigma standard deviation. Depth was converted to pressure assuming a hydrostatic gradient, and vertical error bars indicate the difference between hydrostatic and boiling pressure gradient. The colored curves show the temperature profiles obtained in four boreholes at Tolhuaca. The orange circle shows the estimated reservoir conditions.

Fig. 5. External and internal triggers for gold precipitation. (A), Seismically-triggered and internally-forced fluid pathways in P-H space. The red curves show the calculated gold solubilities in parts per billion ( $\mathrm{ppb}$ ) within the single-phase and two-phase ( $\mathrm{L}+\mathrm{V}$, light blue) fields. The blue arrow shows the adiabatic pressure drop from metastable reservoir conditions (orange circle) to lower pressures (blue/white circles), triggered by a suction pump-like 
mechanism for different earthquake magnitudes (Mw). Shaded in yellow is the optimal range for gold precipitation triggered by adiabatic pressure decrease ( $\mathrm{P} \sim \mathrm{Psat}$ and $\mathrm{P}<150$ bar).

Fig. 6. Gold precipitation efficiency in pressure-enthalpy space. (A), Gold precipitation efficiency (\%) driven by adiabatic pressure drop (red arrow and solid red curves) and (ii) isobaric cooling (green arrow and dashed green curves), considering liquid saturated conditions as a starting point. Transient fluid pressures (blue circles) triggered by a suction pump mechanism for different earthquake magnitudes $(\mathrm{Mw})$ and different starting temperatures (200, 250, 300 and $370^{\circ} \mathrm{C}$; orange circles) are shown for reference. Adiabatic pressure drops have the highest efficiencies at $\mathrm{P}_{\text {sat }}<100$ bar, whereas isobaric cooling requires a significant temperature decrease $\left(\Delta \mathrm{T} \sim 150^{\circ} \mathrm{C}\right)$ to precipitate most of the dissolved gold. (B), Gold solubility along six adiabatic paths (colored curves) and under boiling conditions (black curve). The enthalpy of the fluid was converted to the equivalent temperature at saturated liquid conditions. (C), Quartz solubility in P-H space depicting its prograde $\left(150<\mathrm{T}<350^{\circ} \mathrm{C}\right)$ and retrograde $\left(\mathrm{T}>350^{\circ} \mathrm{C}\right)$ behavior. Thermodynamic data from Manning (1994) (D), Gold-quartz mass ratio resulting from precipitation driven by adiabatic pressure drop and isobaric cooling. The calculated gold-quartz mass ratio represents the gold grade in an idealized quartz vein. Results are consistent with reported data of gold content in gold-rich $(>10 \mathrm{ppm} \mathrm{Au})$ and gold-poor $(<1 \mathrm{ppm} \mathrm{Au})$ quartz veins (Sillitoe and Hedenquist, 2003; Simmons et al., 2005).

\section{Fig. 7. Time-integrated contribution of earthquakes to gold precipitation rates. (A), Co-} seismic volume increase in a jog for different earthquakes magnitudes (Mw). Calculations are based on Weatherley \& Henley (2013). (B), Incremental magnitude-frequency distribution in the 
LOFS, Chile (Lange et al., 2008). Seismicity in Salton Sea, Milos and Wairakei (WK) geothermal systems are shown as a reference. $(\mathbf{C})$, Time-integrated contribution of earthquaketriggered precipitation to gold deposits formation in a time span of $1 \mathrm{ka}$, for a fluid containing 1 ppb of gold using LOFS incremental magnitude-frequency distribution as reference for calculation.

\section{Fig. 8. Gold precipitation rates triggered by the suction pump mechanism during} earthquakes. Gold precipitation rates (magenta diagonal lines, in tonnes (t) per 1000 years (ka)) are plotted as a function of gold content of the fluid (in ppb) and earthquake density distribution relative to the LOFS. The upper limits for gold content in hydrothermal fluids from geothermal systems and epithermal gold deposits are shown as vertical segmented lines for comparison (Taupo Volcanic Zone, Lihir and maximum solubility data were taken from Simmons and Brown, 2006, 2007; Hurtig and Williams-Jones, 2014). Seismicity at Salton Sea (SS), Milos and Wairakei (WK) geothermal systems are shown for reference. The light-red shaded region constrains the window of seismicity vs. gold precipitation at Tolhuaca.

\section{References cited}

Arnórsson, S., Sigurdsson, S., Svavarsson, H., 1982. The chemistry of geothermal waters in Iceland. I. Calculation of aqueous speciation from $0^{\circ} \mathrm{C}$ to $370^{\circ} \mathrm{C}$. Geochim. Cosmochim Acta, 46, 1513 - 1532 . Cembrano, J., Lara, L., 2009. The link between volcanism and tectonics in the southern volcanic zone of the Chilean Andes: A review. Tectonophysics 471, 96-113. doi:10.1016/j.tecto.2009.02.038

Cox, S.F., Ruming, K., 2004. The St Ives mesothermal gold system, Western Australia - a case of golden aftershocks? J. Struct. Geol. 26, 1109-1125. doi:10.1016/j.jsg.2003.11.025 
Hayba, D.O., Ingebritsen, S.E., 1997. Multiphase groundwater flow near cooling plutons. J. Geophys. Res. 102, 12235. doi:10.1029/97JB00552

Heinrich, C.A., 2005. The physical and chemical evolution of low-salinity magmatic fluids at the porphyry to epithermal transition: a thermodynamic study. Miner. Depos. 39, 864-889. doi:10.1007/s00126-004-0461-9

Henley, R., Hughes, G., 2000. Underground fumaroles:“Excess heat” effects in vein formation. Econ. Geol. 95, 453-466.

Holmgren, M., 2007. XSteam: Water and Steam Properties According to IAPWS IF-97.

Hummel, W., Berner, U., Curti, E., Pearson, F.J., Thoenen, T., 2002. Nagra/PSI Chemical Thermodynamic Data Base 01/01. Nagra NTB 02-16, Nagra, Wettingen, Switzerland.

Hurtig, N.C., Williams-Jones, A.E., 2014. An experimental study of the transport of gold through hydration of $\mathrm{AuCl}$ in aqueous vapour and vapour-like fluids. Geochim. Cosmochim. Acta 127, 305325. doi:10.1016/j.gca.2013.11.029

Izawa, E., Urashima, Y., Ibaraki, K., Suzuki, R., Yokoyama, T., Kawasaki, K., Koga, A., and Taguchi, S., 1990, The Hishikari gold deposit: High-grade epithermal veins in Quaternary volcanics of southern Kyushu, Japan: Journal of Geochemical Exploration, v. 36, p. 1-56

Johnson, J.W., Oelkers, E.H., Helgeson, H.C., 1992. SUPCRT92: A software package for calculating the standard molal thermodynamic properties of minerals, gases, aqueous species, and reactions from 1 to 5000 bar and 0 to $1000^{\circ}$ C. Comput. Geosci. 18, 899-947. doi:10.1016/0098-3004(92)90029-Q

Kulik, D. a., Wagner, T., Dmytrieva, S. V., Kosakowski, G., Hingerl, F.F., Chudnenko, K. V., Berner, U.R., 2012. GEM-Selektor geochemical modeling package: revised algorithm and GEMS3K numerical kernel for coupled simulation codes. Comput. Geosci. 1-24. doi:10.1007/s10596-012$9310-6$

Lange, D., Cembrano, J., Rietbrock, A., Haberland, C., Dahm, T., Bataille, K., 2008. First seismic record for intra-arc strike-slip tectonics along the Liquiñe-Ofqui fault zone at the obliquely convergent plate margin of the southern Andes. Tectonophysics 455, 14-24. doi:10.1016/j.tecto.2008.04.014 
Legrand, D., Barrientos, S., Bataille, K., Cembrano, J., Pavez, a., 2011. The fluid-driven tectonic swarm of Aysen Fjord, Chile (2007) associated with two earthquakes (Mw=6.1 and $\mathrm{Mw}=6.2)$ within the Liquiñe-Ofqui Fault Zone. Cont. Shelf Res. 31, 154-161. doi:10.1016/j.csr.2010.05.008

Leonard, M., 2010. Earthquake Fault Scaling: Self-Consistent Relating of Rupture Length, Width, Average Displacement, and Moment Release. Bull. Seismol. Soc. Am. 100, 1971-1988. doi:10.1785/0120090189

Leonard, M., 2012. Erratum to: Earthquake Fault Scaling: Self-Consistent Relating of Rupture Length, Width, Average Displacement, and Moment Release. Bull. Seismol. Soc. Am. 102, 2797-2797. doi:10.1785/0120120249

Leonard, M., 2014. Self-Consistent Earthquake Fault-Scaling Relations: Update and Extension to Stable Continental Strike-Slip Faults. Bull. Seismol. Soc. Am. 104, 2953-2965. doi:10.1785/0120140087

Manning, C.E., 1994. The solubility of quartz in H2O in the lower crust and upper mantle. Geochim. Cosmochim. Acta 58, 4831-4839. doi:10.1016/0016-7037(94)90214-3

Márquez-Zavalía, M. F., \& Heinrich, C. A. (2016). Fluid evolution in a volcanic-hosted epithermal carbonate-base metal-gold vein system: Alto de la Blenda, Farallón Negro, Argentina. Mineralium Deposita. doi:10.1007/s00126-016-0639-y

Mauk, J. L., Hall, C. M., Chesley, J. T., \& Barra, F. (2011). Punctuated evolution of a large epithermal province: The Hauraki goldfield, New Zealand. Economic Geology, 106(6), 921-943. doi:10.2113/econgeo.106.6.921

Melosh, G., Moore, J., Stacey, R., 2012. Natural reservoir evolution in the Tolhuaca geothermal field, southern Chile, in: 37th Workshop on Geothermal Reservoir Engineering Stanford University, Stanford, California, January 31 - February 1, 2012. SGP-TR-194.

Micklethwaite, S., Ford, a., Witt, W., Sheldon, H. a., 2015. The where and how of faults, fluids and permeability - insights from fault stepovers, scaling properties and gold mineralisation. Geofluids 15, 240-251. doi:10.1111/gfl.12102 
Moncada, D., Mutchler, S., Nieto, a., Reynolds, T.J., Rimstidt, J.D., Bodnar, R.J., 2012. Mineral textures and fluid inclusion petrography of the epithermal $\mathrm{Ag}-\mathrm{Au}$ deposits at Guanajuato, Mexico:

Application to exploration. J. Geochemical Explor. 114, 20-35. doi:10.1016/j.gexplo.2011.12.001

Perez-Flores, P., Veloso, E.E., Cembrano, J.M., Sánchez, P., Iriarte, S., Lohmar, S., 2013. Paleomagnetic Reorientation of Structural Elements in Drill Cores: an example from Tolhuaca Geothermal Field (abstract), in: AGU Fall Meeting Abstracts.

Perez-Flores, P., Cembrano, J., Sanchez, P., Veloso, E., Arancibia, G., \& Roquer, T. (2016). Tectonics, magmatism and paleo-fluid distribution in a strike-slip setting: Insights from the northern termination of the Liquiñe-Ofqui fault System, Chile. Tectonophysics, 680, 192-210. doi:10.1016/j.tecto.2016.05.016

Richards, J.P., 2013. Giant ore deposits formed by optimal alignments and combinations of geological processes. Nat. Geosci. 6, 911-916. doi:10.1038/ngeo1920

Rowland, J. V., Simmons, S.F., 2012. Hydrologic, Magmatic, and Tectonic Controls on Hydrothermal Flow, Taupo Volcanic Zone, New Zealand: Implications for the Formation of Epithermal Vein Deposits. Econ. Geol. 107, 427-457. doi:10.2113/econgeo.107.3.427

Sánchez, P., Pérez-Flores, P., Arancibia, G., Cembrano, J., Reich, M., 2013. Crustal deformation effects on the chemical evolution of geothermal systems: the intra-arc Liquiñe-Ofqui fault system, Southern Andes. Int. Geol. Rev. 55, 1384-1400. doi:10.1080/00206814.2013.775731

Sánchez, P., Reich, M., Arancibia, G., Pérez-Flores, P., Cembrano, J., Driesner, T., Lizama, M., Rowland, J., Morata, D., Heinrich, C. A., Tardani, D., Campos, E. 2016, Physical, chemical and mineralogical evolution of the Tolhuaca geothermal system, southern Andes, Chile: insights into the interplay between hydrothermal alteration and brittle deformation. J. Volcanol. Geotherm. Res. doi:10.1016/j.jvolgeores.2016.05.009 Sanematsu, K., Watanabe, K., Duncan, R. A., \& Izawa, E. (2006). The history of vein formation determined by 40Ar/39AR dating of adularia in the Hosen-1 
vein at the Hishikari epithermal gold deposit, Japan. Economic Geology, 101(3), 685-698. doi:10.2113/gsecongeo.101.3.685

Schorlemmer, D., Wiemer, S., Wyss, M., 2005. Variations in earthquake-size distribution across different stress regimes. Nature 437, 539-542. doi:10.1038/nature04094

Sibson, R.., Scott, J., 1998. Stress/fault controls on the containment and release of overpressured fluids: Examples from gold-quartz vein systems in Juneau, Alaska; Victoria, Australia and Otago, New Zealand. Ore Geol. Rev. 13, 293-306. doi:10.1016/S0169-1368(97)00023-1

Sibson, R.H., 1987. Earthquake rupturing as a mineralizing agent in hydrothermal systems. Geology 15, 701. doi:10.1130/0091-7613(1987)15<701:ERAAMA>2.0.CO;2

Sibson, R.H., 2003. Brittle-failure controls on maximum sustainable overpressure in different tectonic regimes. Am. Assoc. Pet. Geol. Bull. 87, 901-908. doi:10.1306/01290300181

Sibson, R.H., Robert, F., Poulsen, K.H., 1988. High-angle reverse faults, fluid-pressure cycling, and mesothermal gold-quartz deposits. Geology 16, 551. doi:10.1130/0091-7613(1988)016<0551

Sillitoe, R., Hedenquist, J., 2003. Linkages between volcanotectonic settings, ore-fluid compositions, and epithermal precious metal deposits, in: Simmons, S.F., Graham, I. (Eds.), Volcanic, Geothermal and Oreforming Fluids; Rulers and Witnesses of Processes within the Earth. Society of Economic Geologists Special Publication 10, pp. 315-343.

Simmons, S.F., White, N., John, D., 2005. Geological characteristics of epithermal precious and base metal deposits. Econ. Geol. 100th Anni, 485-522.

Stefánsson, A., Seward, T.M., 2003a. The hydrolysis of gold(I) in aqueous solutions to $600^{\circ} \mathrm{c}$ and 1500 bar. Geochim. Cosmochim. Acta 67, 1677-1688. doi:10.1016/S0016-7037(02)01131-6

Stefánsson, A., Seward, T.M., 2003b. Stability of chloridogold(I) complexes in aqueous solutions from 300 to $600^{\circ} \mathrm{C}$ and from 500 to 1800 bar. Geochim. Cosmochim. Acta 67, 4559-4576. doi:10.1016/S0016-7037(03)00391-0

Stefánsson, A., Seward, T.M., 2004. Gold(I) complexing in aqueous sulphide solutions to $500^{\circ} \mathrm{C}$ at 500 bar. Geochim. Cosmochim. Acta 68, 4121-4143. doi:10.1016/j.gca.2004.04.006 
Tardani, D., Reich, M., Roulleau, E., Takahata, N., Sano, Y., Peréz-Flóres, P., Sanchez-Alfaro, P... Arancibia, G. (2016). Exploring the structural controls on helium, nitrogen and carbon isotope signatures in hydrothermal fluids along an intra-arc fault system. Geochimica et Cosmochimica Acta, 184, 193-211. doi:10.1016/j.gca.2016.04.031

Weatherley, D.K., Henley, R.W., 2013. Flash vaporization during earthquakes evidenced by gold deposits. Nat. Geosci. 6, 294-298. doi:10.1038/ngeo1759

Weis, P., Driesner, T., Heinrich, C.A., 2012. Porphyry-copper ore shells form at stable pressuretemperature fronts within dynamic fluid plumes. Science 338, 1613-6. doi:10.1126/science.1225009

Williams-Jones, A.E., Bowell, R.J., Migdisov, a. a., 2009. Gold in Solution. Elements 5, 281-287. doi:10.2113/gselements.5.5.281 


\section{Figure 1}
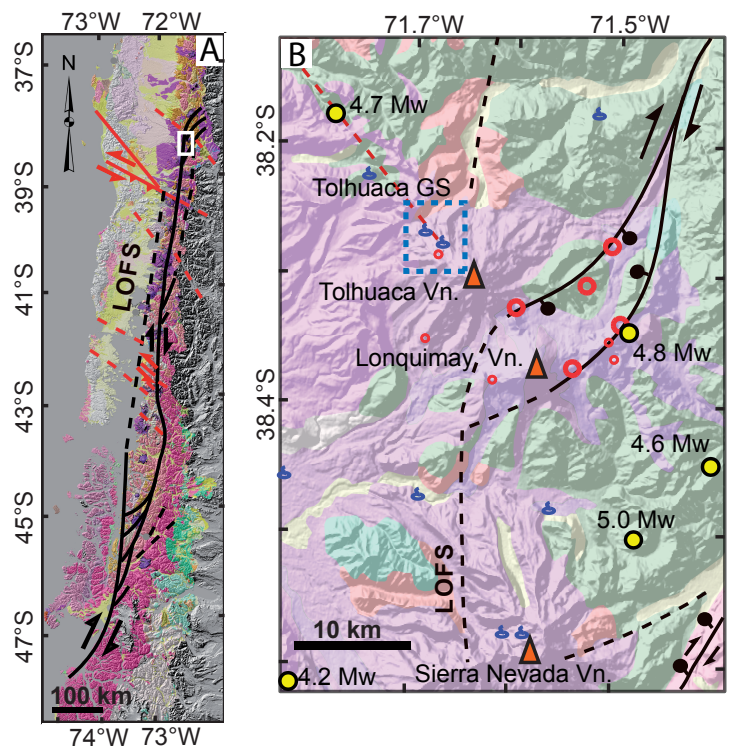

Legend

Quaternary volcanic rocks

Oligocene-Miocene

Volcano-sedimentary rocks

Miocene-Cretaceous batholith

Cretaceous-Paleogene Sedimentary rocks

Jurassic volcano-sedimentary

$\Delta$ Volcano

- Minor eruptive center/

- Thermal spring / fumarole

O Seismic event (<33 km depth)

Liquiñe-Ofqui Fault

System (LOFS)

7/2 Dextral strike slip fault

Andean Transverse

Structures (ATS)

\$ Sinistral-reverse

Inferred faults
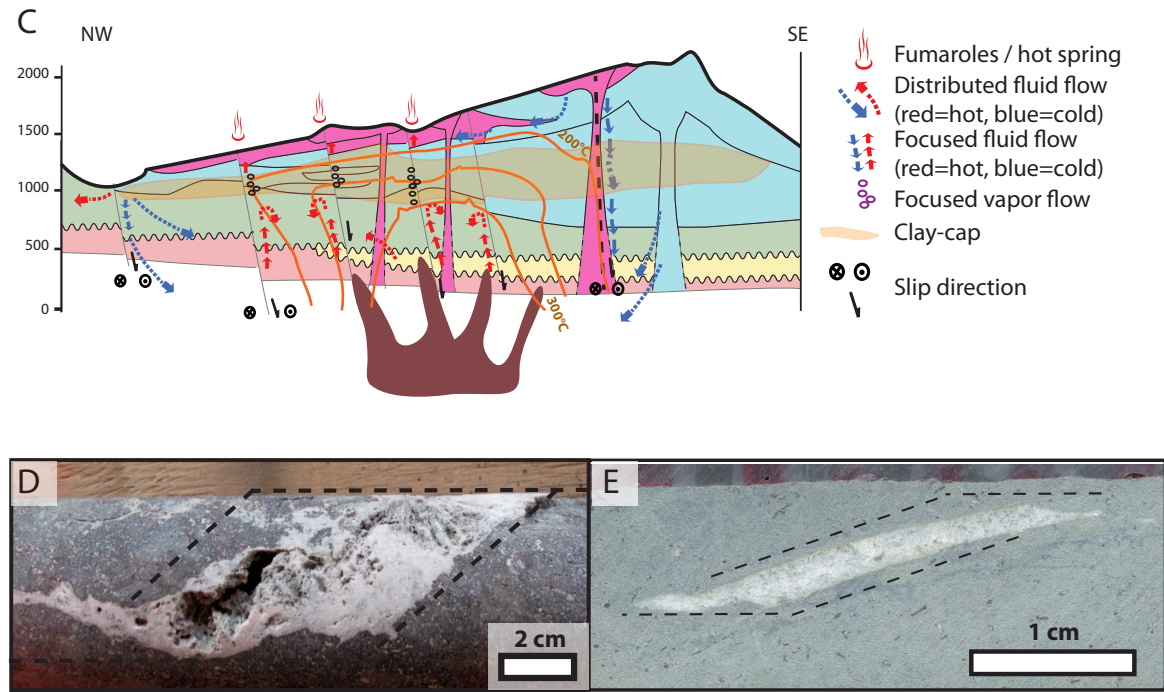
Figure 2

\section{A Pre-rupture}

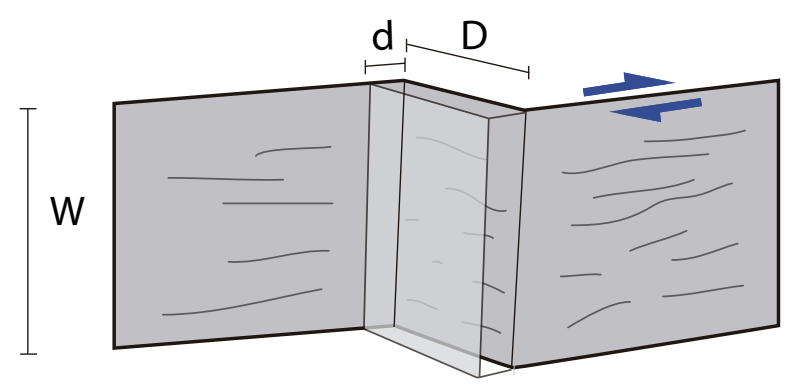

\section{B Post-rupture}

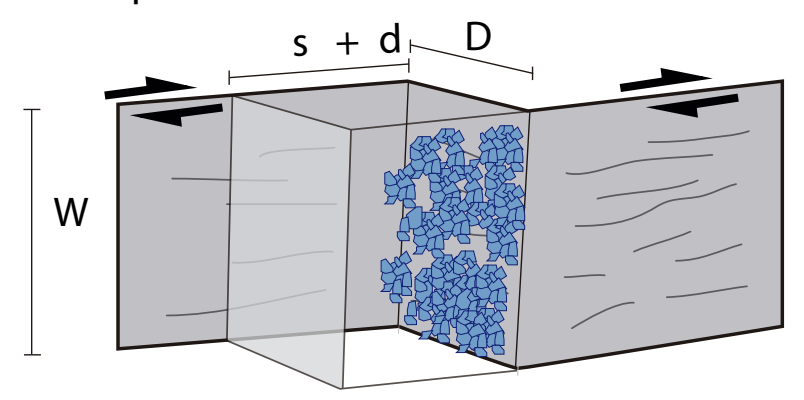




\section{Figure 3}

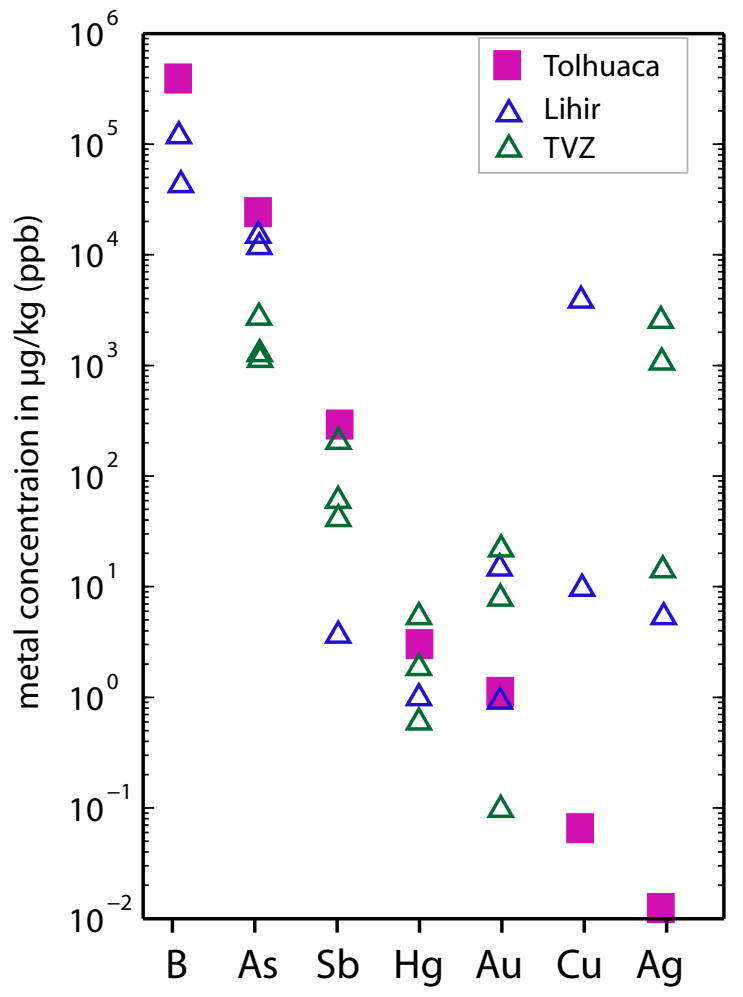




\section{Figure 4}
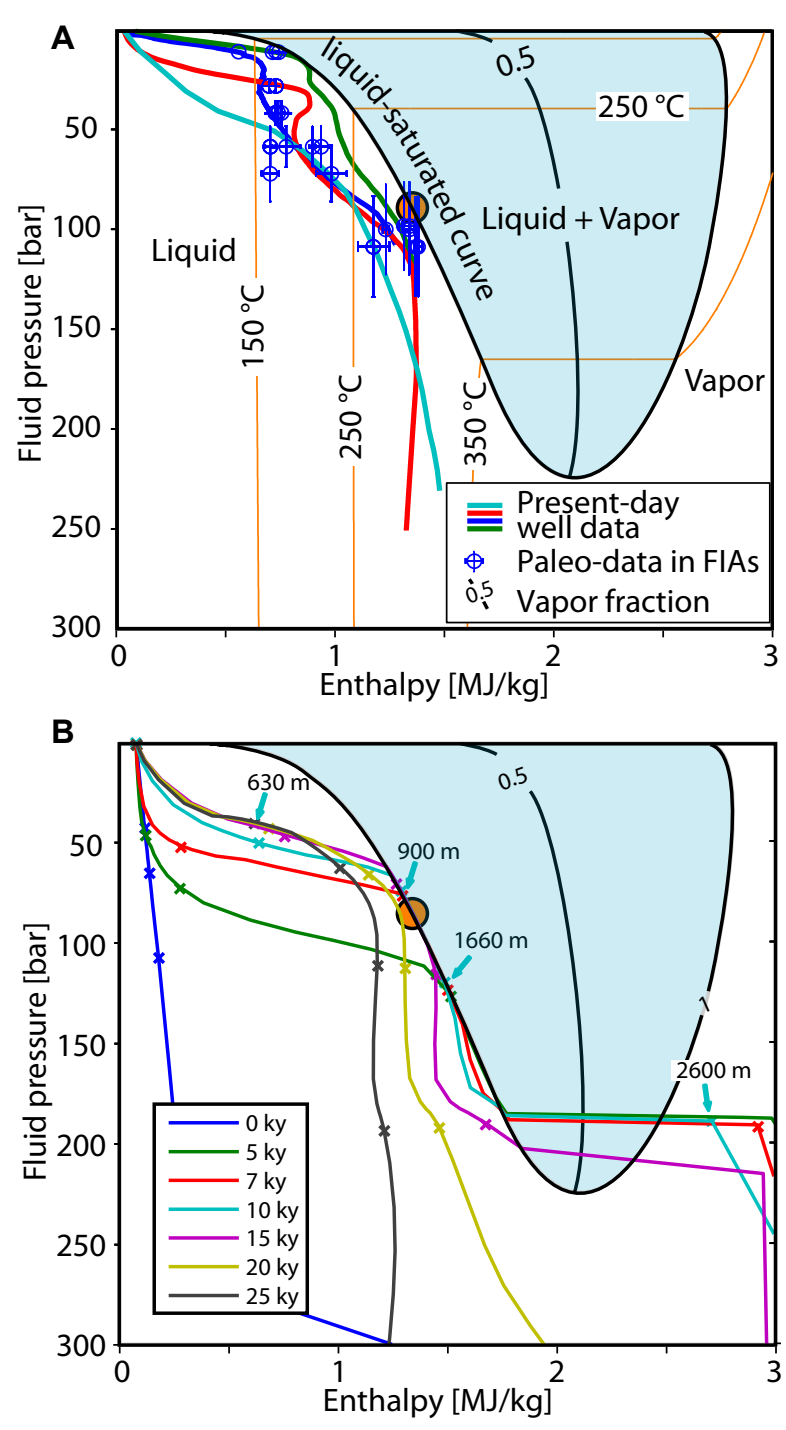
Figure 5

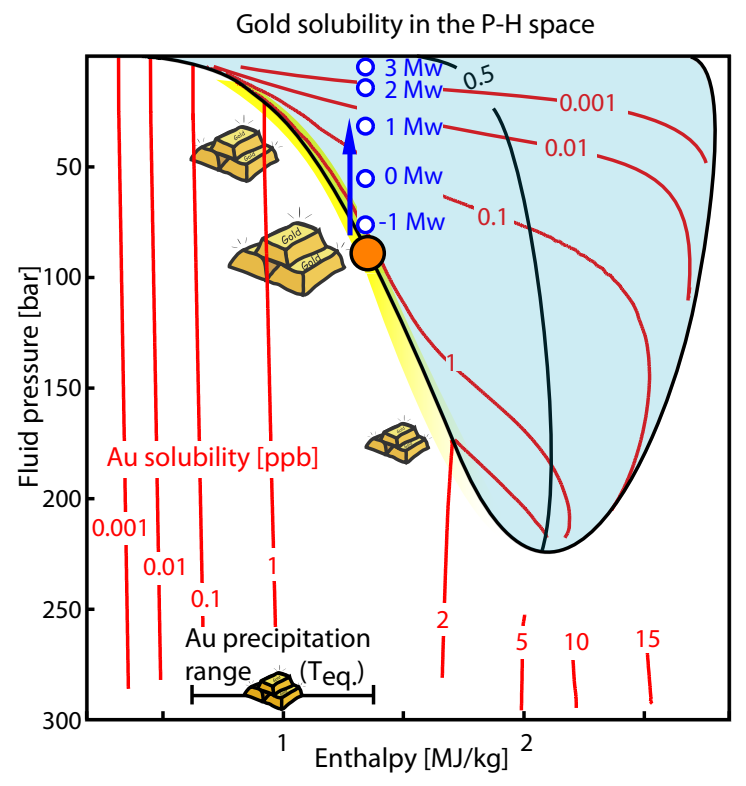



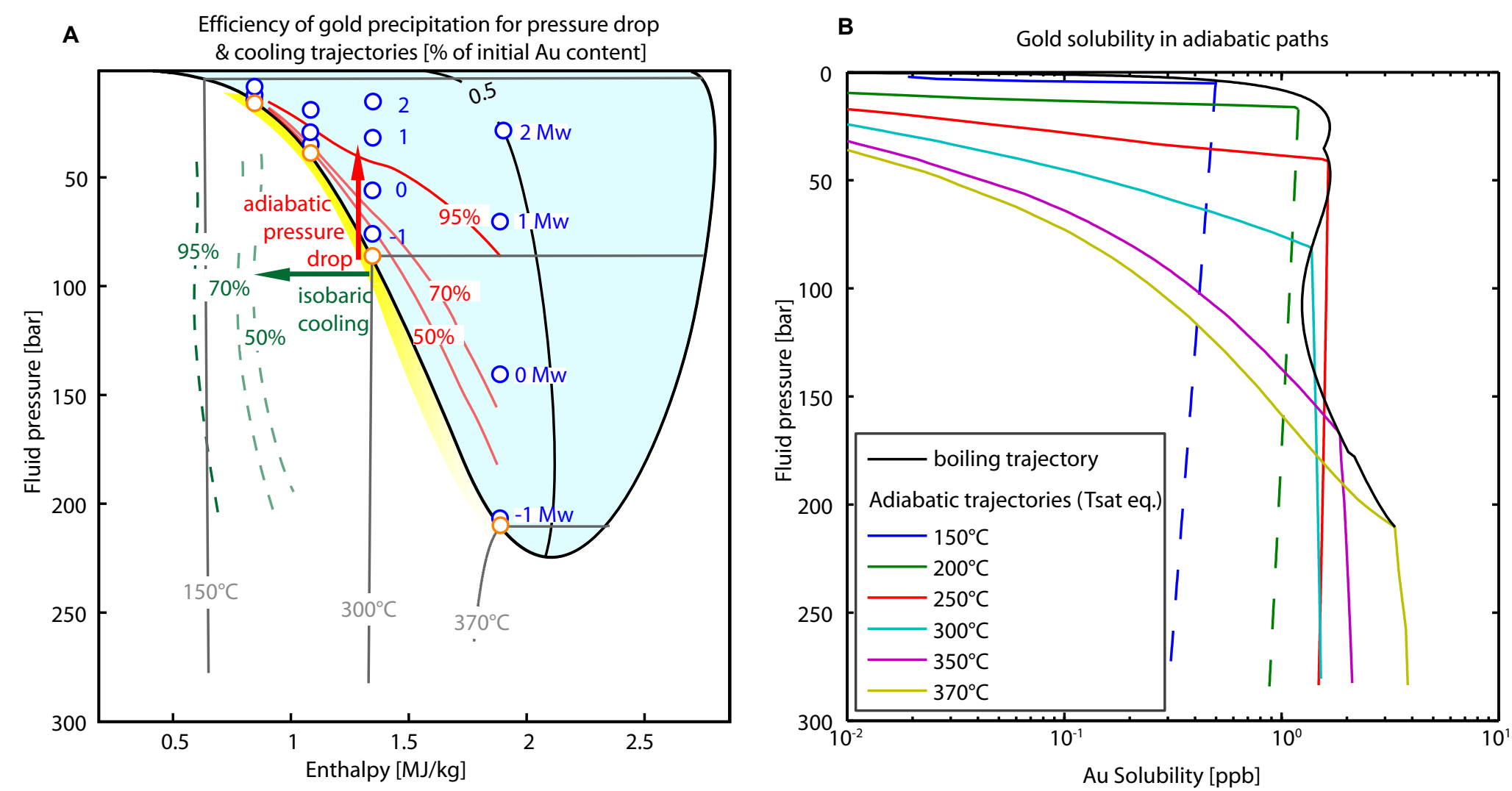

C

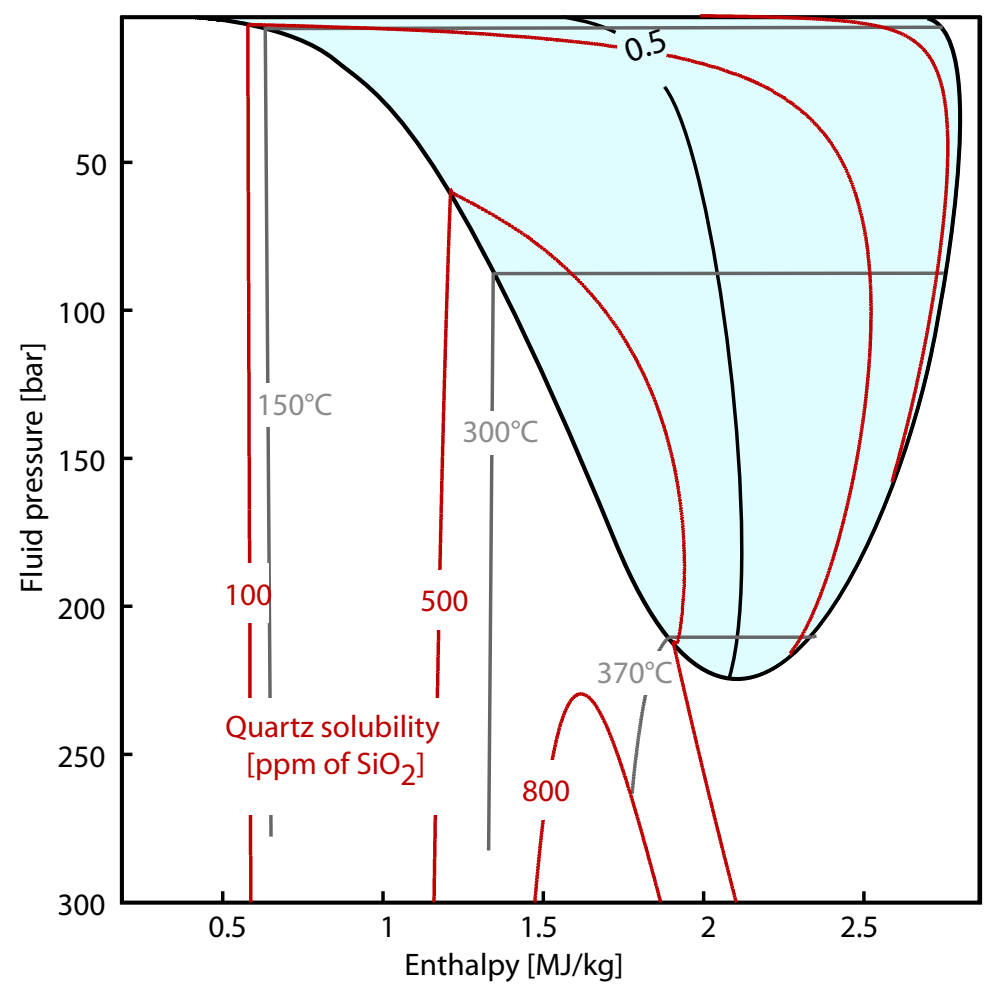

Gold-quartz mass ratio when precipitation is driven by pressure drop or cooling

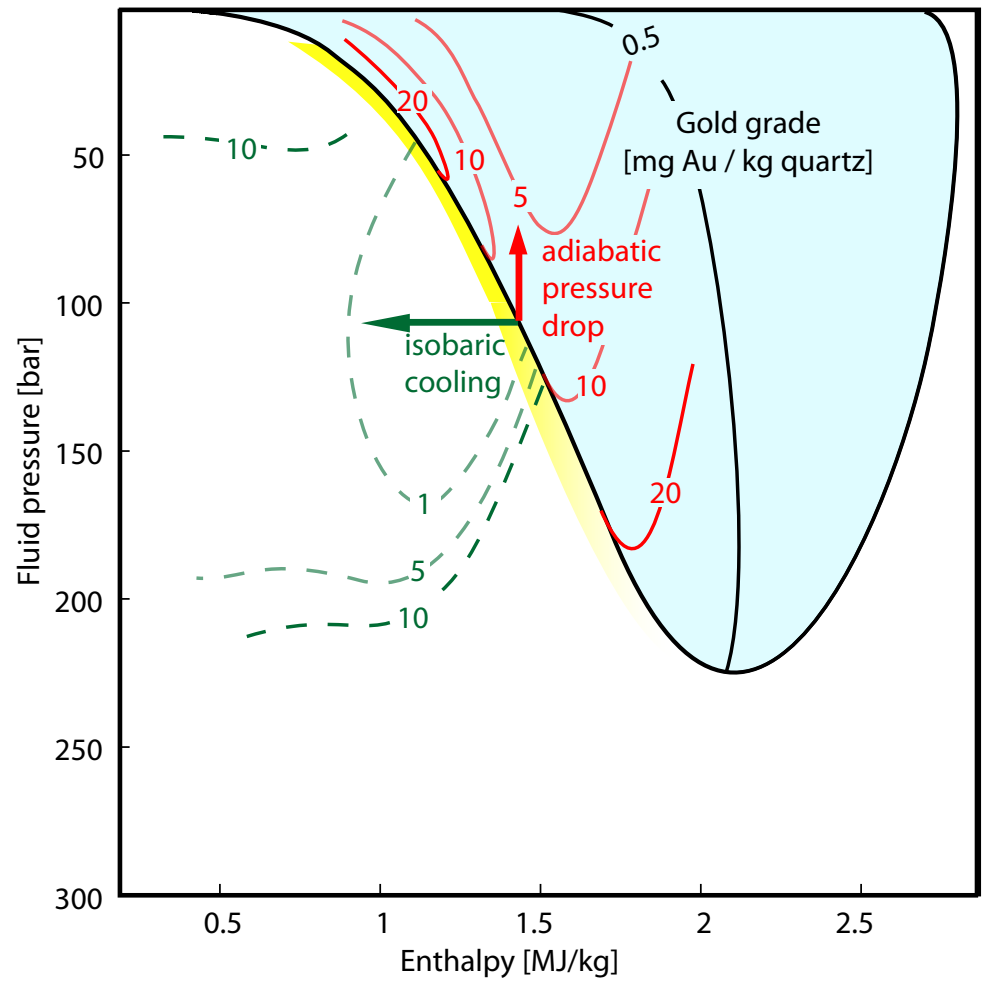




\section{Figure 7}

A

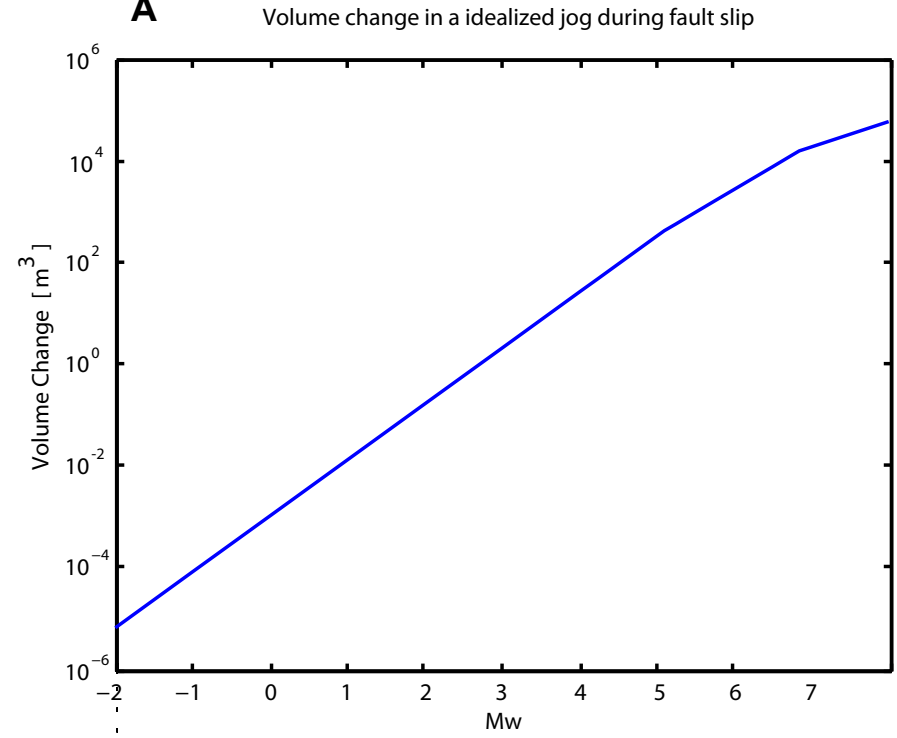

B Incremental magnitude-frequency distribution in the LOFS and other geothermal systems

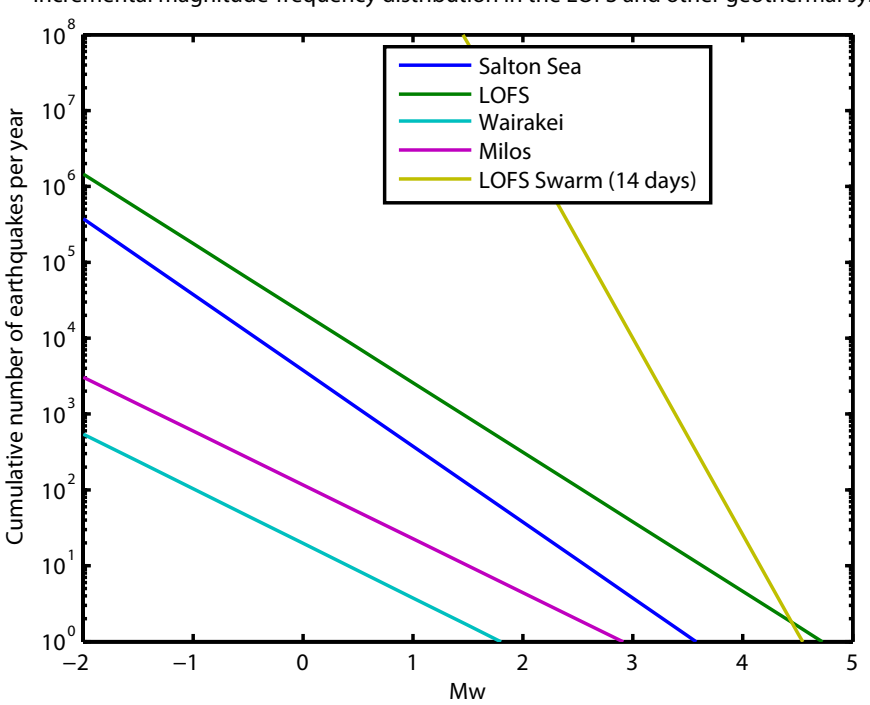

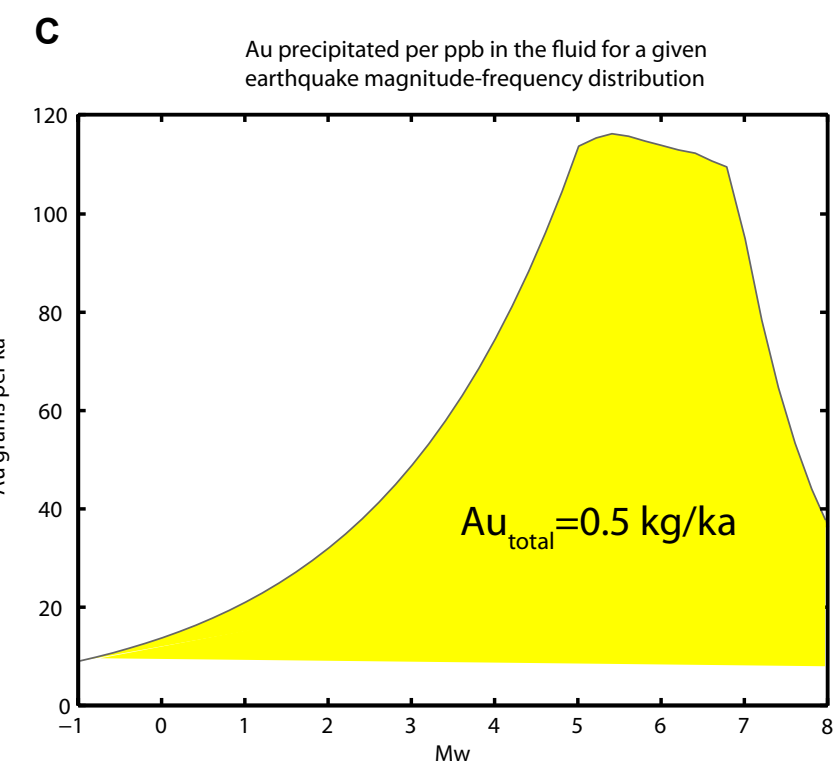




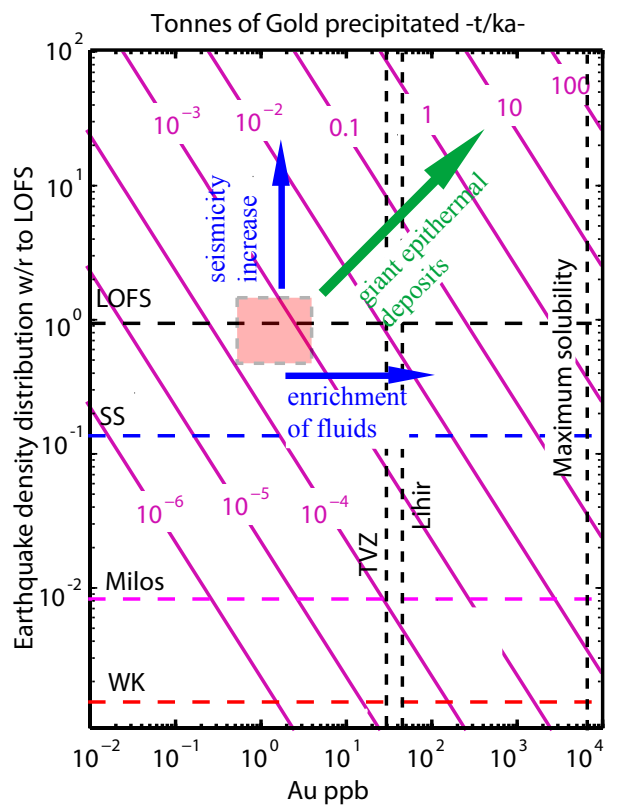


Graphical abstract

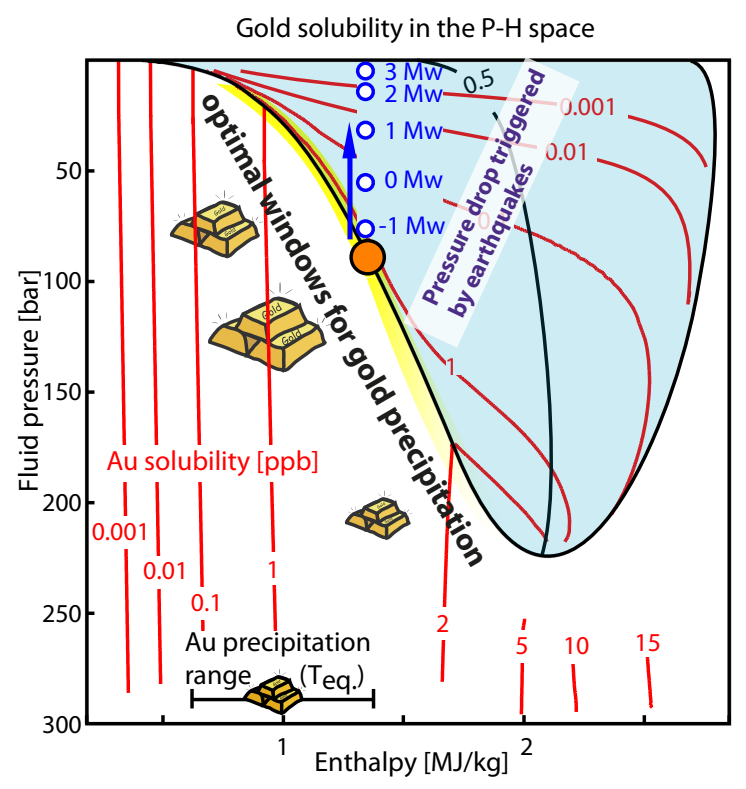

